\title{
Post Transplantation Lymphoproliferative Disorder (PTLD) Presenting as Biliary Duct Obstruction
}

\author{
Isabelle Morard ${ }^{1,2, *}$, Gilles Mentha ${ }^{2,3}$, Laura Rubbia $^{4}$, Sylvain Terraz $^{5}$, Laurent Spahr ${ }^{1}$, \\ Antoine Hadengue ${ }^{1}$, Pietro Majno ${ }^{2,3}{\text { Philippe } \text { Morel }^{2,3} \text { and Emiliano Giostra }}^{1,2}$
}

\author{
${ }^{1}$ Hepatogastroenterology, ${ }^{2}$ Transplantation, ${ }^{3}$ Visceral Surgery, ${ }^{4}$ Anatomopathology, ${ }^{5}$ Radiology, Hôpitaux Universi- \\ taires de Genève, Geneva, Switzerland
}

\begin{abstract}
After adult liver transplantation (LT), post-transplant lymphoproliferative disorder (PTLD) is an uncommon but serious complication of immunosuppression (IMS) in presence of an acute or latent EBV infection. The clinical presentation of this disease is aspecific, and, after LT, it may mimic anastomotic bile duct stricture.

We report the cases of 2 adult patients who developed, 3 months and 8 years after OLT, an EBV-associated PTLD with diffuse intrinsic infiltration of bile duct mimicking anastomotic biliary stricture. In the absence of liver or hilar nodes involvement, percutaneous biopsies were non contributive and the diagnosis were made by surgical biopsy. After reduction of IMS and Rituximab treatment, both patients are alive without recurrence 5 and 6 years after diagnosis.

In conclusion, PTLD is one of the differential diagnosis of biliary tree obstruction after OLT. Diagnosis requires surgical biopsies and treatment consists in IMS reduction and Rituximab.
\end{abstract}

\section{INTRODUCTION}

Post-transplant lymphoproliferative disorder (PTLD) which occurs in about $10 \%$ of pediatric liver allograft recipients, is an uncommon complication after adult liver transplantation (LT) (0.5-4.3\%) [1-4]. The majority of PTLD are linked to acute or latent Epstein-Barr virus (EBV) infection and the main risk factors are both the type and the intensity of immunosuppression (IMS). The rare cases of EBVnegative PTLD tend to occur later after the transplant, and behave more aggressively [2].

The spectrum of presentation of PTLD varies from localized to disseminated involvement and may concern lymph nodes, allograft organ or sites of surgical intervention [1-5].

We report the cases of 2 adult patients who developed, 3 months and 8 years after OLT, an EBV-associated PTLD mimicking anastomotic biliary stricture.

\section{CASE REPORTS}

\section{Patient 1}

In April 2002, a 52-year-old man underwent LT for alcoholic cirrhosis and hepatocarcinoma (HCC). He was CMV and EBV IgG positive, and IgM negative. The initial IMS regimen consisted in $20 \mathrm{mg}$ of Basiliximab on day 1 and 4, mycophenolate mofetil (MMF) $250 \mathrm{mg}$ bid and Cyclosporin (CyA) with target through levels of $200 \mu \mathrm{g} / \mathrm{l}$.

Two weeks after LT, the patient developed an asymptomatic CMV infection treated with intravenous ganciclovir (5 $\mathrm{mg} / \mathrm{kg}$ bid).

*Address correspondence to this author at the Hepatogastroenterology, Hôpitaux Universitaires de Genève, Geneva, Switzerland;

E-mail: Isabelle.Morard@hcuge.ch
Three months after LT, the patient presented with a cholestasis (GGT $5 \mathrm{~N}$, alkaline phosphatase $1.5 \mathrm{~N}$ ) and bilirubin $61 \mu \mathrm{mol} / \mathrm{l}$. Abdominal ultrasound, cholangio-RMI, CT-scan and percutaneous cholangiogram showed a long stenosis of the bilio-biliary anastomosis and an enlargement of the intrahepatic biliary ducts (image 1). The patient underwent surgical resection of the stenosis with confection of a jejunobiliary anastomosis. Histological analysis showed a peribiliary and biliary infiltration by numerous B lymphoblasts and some lymphocytes (image 2). Immunohistochemical

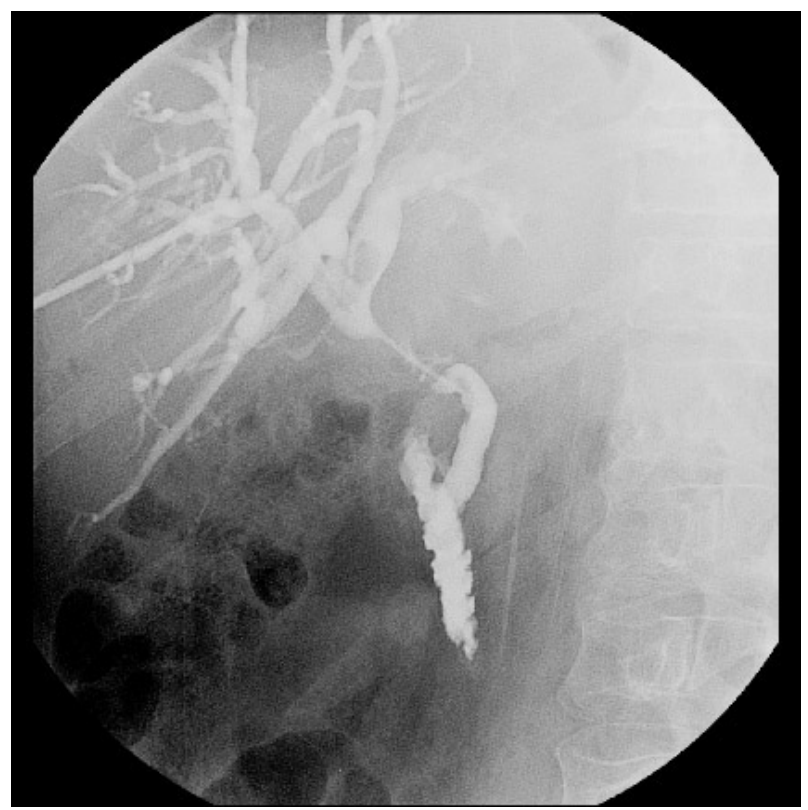

Image 1: Patient 1: percutaneous cholangiogram showing an enlargement of the intrahepatic biliary ducts 


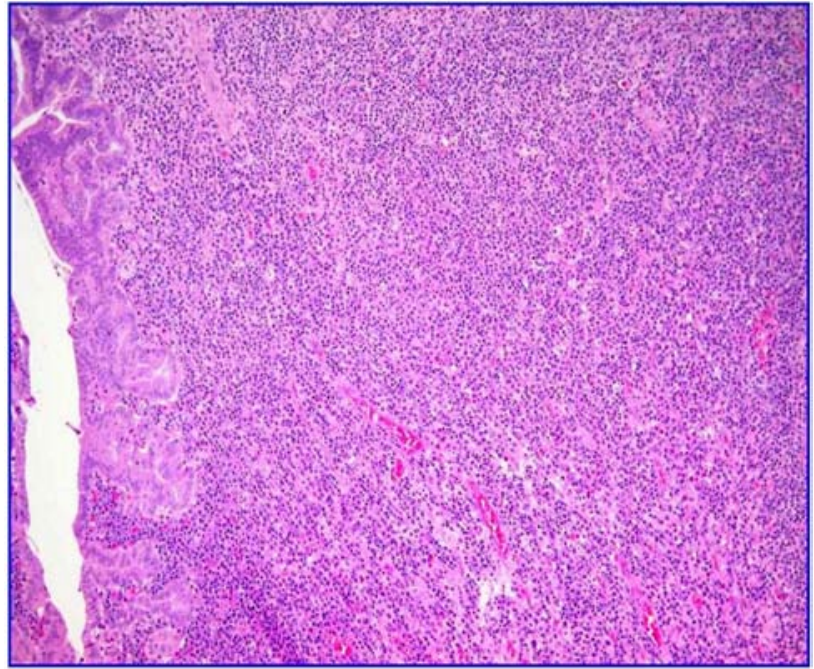

Image 2: Patient 1: Histological analysis showing a peri-biliary and biliary infiltration by a PTLD of polymorphic B lymphoblasts.

stains were positive for CD-20 (B-cell marker) and negative for CD-3 (T-cell marker). The ratio of kappa/lambda immunoglobulines was 10/1. Research of immunoglobulines genes rearrangement by PCR identified one clonal population of $\mathrm{B}$ cells. EBV was positive by EBER, EBNA2, EBNA3 and viral DNA by real time PCR was strongly positive in the biopsy (1,2 mio EBV copies per microgram of DNA) but undetectable in the serum. The diagnosis of an EBVassociated B-cell polymorphic PTLD was made [6,7]. A thoraco-abdominal CT-scan excluded other tumoral localizations. MMF was discontinued and CyA decreased (through level of $80 \mu \mathrm{mol} / \mathrm{l}$ ) and rituximab was administrated weekly for 1 month followed by 4 monthly injections of $375 \mathrm{mg} / \mathrm{m}^{2}$.

Six years after the diagnosis, the patient was treated with CyA (through level $50 \mu \mathrm{g} / \mathrm{l}$ ) and MMF (250 mg bid). Physical examination, total body CT-scan, liver biopsy and liver function have been normal for 6 years without evidence of rejection or PTLD recurrence.

\section{Patient 2}

In February 1995, a 24 year-old man underwent LT for primary sclerosis cholangitis. He was CMV negative and EBV IgG positive. Initial IMS consisted of CyA (through level 200-336 $\mu \mathrm{g} / \mathrm{l}$ during the first year, below $100 \mu \mathrm{g} / \mathrm{l}$ during the second year) methylprednisolone $(20 \mathrm{mg} / \mathrm{d}$ initially, stopped 17 months after LT), and azathioprine $(200 \mathrm{mg} / \mathrm{d}$ initially, $75 \mathrm{mg} / \mathrm{d}$ at the end of the first year, $50 \mathrm{mg} / \mathrm{d}$ from the second to the fourth year).

In January1998, with low levels of IMS (CyA through level below $100 \mu \mathrm{g} / \mathrm{l}$, Azathioprine $50 \mathrm{mg} / \mathrm{d}$ ), the patient presented a moderate acute rejection successfully treated by switching from CyA to Tacrolimus (through levels 10-15 $\mu \mathrm{g} / \mathrm{l})$. Since July 1998 he had fluctuating levels of ALT and AST (2-3 N) with a constant increased GGT (7N) and alkaline phosphatase (2N). Liver biopsy performed in 1998-99 showed portal focal peri-biliary fibrosis and bile ducts proliferation, suggesting either a biliary obstruction or a recurrence of primary cholangitis. Liver tests normalized after switching from Azathioprine $50 \mathrm{mg} / \mathrm{d}$ to MMF $500 \mathrm{mg}$ bid. In February 2002, 7 years after LT, GGT and alkaline phos- phatase increased again ( 7 and $2 \mathrm{~N}$, respectively) with a left intra-hepatic bile duct enlargement. Biopsy showed dystrophic biliary ducts, minimal neoductular proliferation with concentric peri-biliary fibrosis and focally extensive portal fibrosis and cholangiography showed a severe stenosis of the bilio-digestive anastomosis, which was treated by antibiotics, dilatation and drainage. The liver tests improved and biliary obstruction resolved after two months of drainage. Eight months after the drainage-tube removal, the patient presented again with elevated liver enzymes. Biopsy showed a portal, peri portal and lobular non blastic lymphocyte aggregates with portal fibrosis. A new cholangio-RMI disclosed a new, important, stenosis located on the bile ducts convergence. Laparotomy performed in November 2003, revealed an inflammatory thickening of the common, right and left bile ducts walls with obstruction of the common bile duct, and new anastomosis was performed at the roof of the biliary convergence. Histological analysis showed a peri-biliary and biliary infiltration by polymorphic B lymphocytes, lymphoblasts and plasmocytes (image 3), CD 79a and CD20 positive. Repartition of lambda and kappa immunoglobulines was homogenous by immunomarkers, and research of immunoglobulines genes rearrangement by PCR and Southern Blot did not identify clonal population of B cells. Some cells were EBV positive by EBER, EBNA2, EBNA3. EBV DNA by real time PCR was positive in the bile duct but negative in the serum. The diagnosis of polymorphic EBV-associated Bcell PTLD was made [6]. Neck, thoracic and abdominal CTscan as well as bone marrow biopsy excluded extension of the disease. Quantification of EBV DNA by real time PCR in the serum was negative. MMF was discontinued and Tacrolimus was decreased but this was complicated by a rejection (grade 6 according to Banff classification) [8]. Tacrolimus was switched to rapamycine (target levels of $8 \mathrm{mg} / \mathrm{l}$ ) and $20 \mathrm{mg}$ of methylprednisolone were added. Liver tests were progressively improved. One month after surgery rituximab was administrated as 4 weekly injections of 375 $\mathrm{mg} / \mathrm{m}^{2}$ without complication. CT-scan which were, cholangio-MRI and PET-CT scan performed every year during five years did not show tumoral recurrence.

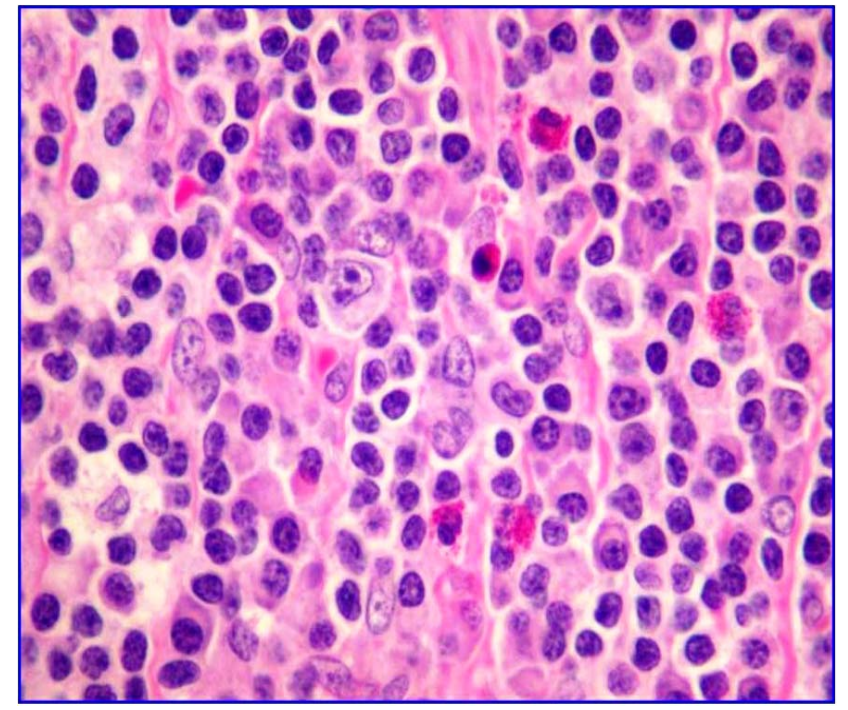

Image 3: Patient 2: Histological analysis showing a peri-biliary infiltration by a PTLD of polymorphic B lymphoblasts, CD20 positive in the resected bile duct. 


\section{DISCUSSION}

Biliary complications occur in about $15 \%$ of patients after LT [9]. Strictures that develop during the first three post operative months are mainly anastomotic, due to local ischemia at the anastomosis or suturing technique. The late biliary strictures and obstruction may be anastomotic, often isolated and short. They may be hilar or intrahepatic, usually more diffuse and severe, evoking the differential diagnosis of arterial occlusion, prolonged cold ischemic time, CMV infection, ABO-incompatible transplantation or recurrence of primary sclerosing cholangitis [9].

We report here the cases of 2 adult patients who developed, 3 months and 8 years after LT, an EBV-associated PTLD mimicking anastomotic biliary stricture. Compression of the bile duct by hilar nodes has been reported in primary lymphoma occurring in non transplant population [10-12]. After liver transplantation, PTLD presenting as a localized single hilar tumor with obstructive jaundice has been described [1, 4, 13-19] in 20 patients. However, diffuse intrinsic infiltration of bile duct by a PTLD is extremely rare: in the series of 16 post liver transplantation PTLD described by Duvoux et al. only one concerned the biliary tract [1].

As PTLD lesions of our patients did involve neither the hepatic parenchyma nor hilar nodes, percutaneous liver biopsies were not contributive and diagnosis was unsuspected until surgery. Endoscopic biopsies performed before dilatation and stenting of the biliary tract could probably have been more informative.

The majority of PTLD are secondary to EBV which may cause an uncontrolled proliferation of B-lymphocytes in the absence of an effective cytotoxic T cells response. EBV genome is present in 68 to $100 \%$ [1,3,5] of adult PTLD, but EBV DNA research by PCR in the serum is often negative.

Despite the fact that surgical biopsy is often the only way to make the diagnosis, the effective treatment of biliary PTLD does not rely on surgery but on the reduction or the complete discontinuation of IMS [3]. To decrease the risk of rejection, the switch from Calcineurine inhibitors (CNI) to mTOR inhibitors should be preferred to complete IMS withdrawal. Immunosuppression by Sirolimus or everolimus, which are active through inhibition of the mTOR pathway, seems to inhibit the proliferation and survival of the PTLD cell-line derived from recipients PTLD [20, 21]. This antiproliferative action could be effective not only in preventing graft rejection but also in controlling lymphocytes proliferation.

In addition to IMS modification, management of PTLD includes Rituximab, a chimeric mouse-human anti CD20 antibody, directed against the surface antigens of both the normal and malignant B-lymphocytes, mediating a complement-dependant cellular lysis with antibody-dependant cellular cytotoxicity. The use of Rituximab was reported in the treatment of PTLD after solid organ transplantation [22, 23] with complete remission up to $87.5 \%$ [23]. Since 2000, five articles reported the use of rituximab in 5 adult and 7 pediatric patients who developed PTLD after LT [24-28]. Treatment was well tolerated and led to complete remission in 4 adult patients [27] and 6 pediatric patients with a follow-up going from 10 weeks to 3 years.

\section{CONCLUSION}

PTLD is a rare but serious complications of immunosuppression in presence of an acute or latent EBV infection. The clinical presentation of this disease is aspecific, and, after OLT, it may mimic anastomotic or nonanastomotic bile duct stricture. Therefore, PTLD is one of the differential diagnoses of biliary tree obstruction after OLT. In this case, laparotomy and surgical biopsies are the only methods to confirm the diagnosis.

\section{REFERENCES}

[1] Duvoux C, Pageaux GP, Vanlemmens C, et al. Risk factors for lymphoproliferative disorders after liver transplantation in adults: an analysis of 480 patients. Transplantation 2002; 74: 1103-9.

[2] Dotti G, Fiocchi R, Motta T, et al. Lymphomas occurring late after solid-organ transplantation: influence of treatment on the clinical outcome. Transplantation 2002; 74: 1095-102.

[3] Jain A, Nalesnik M, Reyes J, et al. Posttransplant lymphoproliferative disorders in liver transplantation: a 20-year experience. Ann Surg 2002; 236: 429-36; discussion 436-7.

[4] Baron TH. Establishing a systematic endoscopic approach to the management of anastomotic biliary strictures is needed. Liver Transpl 2001; 7(4): 378-9.

[5] Doria C, Marino IR, Scott VL, et al. Posttransplant lymphoproliferative disorders presenting at sites of previous surgical intervention. Transplantation 2003; 75: 1066-9.

[6] Harris NL, Jaffe ES, Diebold J, et al. The World Health Organization classification of neoplasms of the hematopoietic and lymphoid tissues: report of the Clinical Advisory Committee meeting--Airlie House, Virginia, November, 1997. Hematol J 2000; 1(1): 53-66.

[7] Knowles DM, Cesarman E, Chadburn A, et al. Correlative morphologic and molecular genetic analysis demonstrates three distinct categories of post transplantation lymphoproliferative disorders. Blood 1995; 85: 552-5651.

[8] Demetris A, Adams D, Bellamy C, et al. Update of the International Banff Schema for Liver Allograft Rejection: working recommendations for the histopathologic staging and reporting of chronic rejection. An International Panel. Hepatology 2000; 31: 792-9.

[9] Moser MA, Wall WJ. Management of biliary problems after liver transplantation. Liver Transplant 2001; 7(11 Suppl 1): S46-52.

[10] Ravindra KV, Stringer MD, Prasad KR, Kinsey SE, Lodge JP. Non-Hodgkin lymphoma presenting with obstructive jaundice. Br J Surg 2003; 90(7): 845-9.

[11] Jho DH, Jho DJ, Chejfec G, Ahn M, Ong ES, Espat NJ. Primary biliary B-cell lymphoma of the cystic duct causing obstructive jaundice. Am Surg 2007; 73(5): 508-10.

[12] Sugawara G, Nagino M, Oda K, Nishio H, Ebata T, Nimura Y. Follicular lymphoma of the extrahepatic bile duct mimicking cholangiocarcinoma. J Hepatobiliary Pancreat Surg 2008; 15(2): 1969.

[13] Moody AR, Wilson SR, Greig PD. Non-Hodgkin lymphoma in the porta hepatis after orthotopic liver transplantation: sonographic findings. Radiology 1992; 182(3): 867-70.

[14] Cherqui D. Lymphoproliferative disorder of donor origin in a liver transplant recipient: complete remission after drastic reduction of immunosuppression without graft loss. Transplantation 1993; 56(4): 1023-6.

[15] Spiro IJ. Brief report: lymphoma of donor origin occurring in the porta hepatis of a transplanted liver. N Engl J Med 1993; 329(1): 27-9.

[16] Armes JE. Lymphoproliferative disease of donor origin arising in patients after orthotopic liver transplantation. Cancer 1994; 74(9): 2436-41.

[17] Ribas Y. Post-transplant lymphoma in a liver allograft. Transplant Int 1995; 8(6): 488-91.

[18] Strazzabosco M. Epstein-Barr virus-associated post-transplant lympho-proliferative disease of donor origin in liver transplant recipients. J Hepatol 1997; 26(4): 926-34.

[19] Navarro F, Pyda P, Pageaux G-P, et al. Lymphoproliferative disease after liver translantation: Primary biliary localization. Transplant Proc 1998: 30(4): 1486-8. 
[20] Majewski M, Korecka M, Joergensen J, et al. Immunosuppressive TOR kinase inhibitor everolimus (RAD) suppresses growth of cells derived from post transplant lymphoproliferative disorder at allograft-protecting doses. Transplantation 2003; 75: 1710-7.

[21] El-Salem M, Raghunath PN, Marzec M, et al. Constitutive activation of mTOR signaling pathway in post-transplant lymphoproliferative disorders. Lab Invest 2007; 87: 29-39.

[22] Ganne V, Siddiqi N, Kamaplath B, et al. Humanized anti-CD20 monoclonal antibody (Rituximab) treatment for post-transplant lymphoproliferative disorder. Clin Transplant 2003; 17: 417-22.

[23] Berney T, Delis S, Kato T, et al. Successful treatment of posttransplant lymphoproliferative disease with prolonged rituximab treatment in intestinal transplant recipients. Transplantation 2002; 74: $1000-6$.

[24] Zompi S, Tulliez M, Conti F, et al. Rituximab (anti-CD20 monoclonal antibody) for the treatment of patients with clonal lymphoproliferative disorders after orthotopic liver transplantation: a report of three cases. J Hepatol 2000; 32: 521-7.

[25] Oertel SH, Anagnostopoulos I, Bechstein WO, Liehr H, Riess HB. Treatment of posttransplant lymphoproliferative disorder with the
anti-CD20 monoclonal antibody rituximab alone in an adult after liver transplantation: a new drug in therapy of patients with posttransplant lymphoproliferative disorder after solid organ transplantation? Transplantation 2000; 69: 430-2.

[26] Serinet MO, Jacquemin E, Habes D, Debray D, Fabre M, Bernard O. Anti-CD20 monoclonal antibody (Rituximab) treatment for Epstein-Barr virus-associated, B-cell lymphoproliferative disease in pediatric liver transplant recipients. J Pediatr Gastroenterol Nutr 2002; 34: 389-93.

[27] Yedibela S, Reck T, Niedobitek G, et al. Anti-CD20 monoclonal antibody treatment of Epstein-Barr virus-induced intrahepatic lymphoproliferative disorder following liver transplantation. Transplant Int 2003;16:197-201.

[28] Al-Akash SI, Al Makadma AS, Al Omari MG. Rapid response to rituximab in a pediatric liver transplant recipient with posttransplant lymphoproliferative disease and maintenance with sirolimus monotherapy. Pediatr Transplant 2005; 9: 249-53.

(C) Morard et al.; Licensee Bentham Open.

This is an open access article licensed under the terms of the Creative Commons Attribution Non-Commercial License (http: //creativecommons.org/licenses/ by-nc/3.0/) which permits unrestricted, non-commercial use, distribution and reproduction in any medium, provided the work is properly cited. 